\title{
Postprandial lipid metabolism: effects of dietary fatty acids
}

\author{
BY CHRISTINE M. WILLIAMS \\ Hugh Sinclair Unit of Human Nutrition, Department of Food Science and Technology, \\ University of Reading, Reading RG6 6AP
}

Current dietary recommendations for fatty acid intakes aimed at reducing the prevalence of CHD are largely based on the cholesterol hypothesis and on the well-established effects of specific fatty acid classes on fasting total cholesterol, LDL and HDL concentrations (Department of Health, 1991, 1994). Increasing recognition of the potential atherogenic and thrombogenic consequences of elevated triacylglycerol-rich lipoproteins (TRL; Cohn, 1994; Havel, 1994; Karpe et al. 1994; Hodis \& Mack, 1995; Karpe \& Hamsten, 1995) has revealed the paucity of dietary studies which evaluate postprandial as well as fasting lipoproteins.

The need for a greater understanding of effects of diet on postprandial lipoproteins is emphasized by the fact that most individuals are in a postprandial state for the greater part of every $24 \mathrm{~h}$ period. A typical $24 \mathrm{~h}$ triacylglycerol profile of a normal individual eating three or four meals and snacks per day is shown in Fig. 1, and illustrates that triacylglycerol levels are elevated above fasting values for approximately $17 \mathrm{~h}$ of each $24 \mathrm{~h}$ period. Only in the early morning between 03.00 and 06.00 hours, do triacylglycerol levels reflect the values measured after a $12 \mathrm{~h}$ fast, the measurement usually made in most epidemiological studies. It is clear that the fasting state does not reflect total $24 \mathrm{~h}$ triacylglycerol values and is not the normal nutritional state for most individuals, at least as far as lipid metabolism is concerned.

\section{POSTPRANDIAL TRIACYLGLYCEROL-RICH LIPOPROTEINS AS A LIPID RISK FACTOR}

The involvement of postprandial TRL (chylomicrons (CM) and VLDL) in the pathogenesis of atherosclerosis and thrombosis is dealt with by other speakers in the symposium (Karpe, 1997; Miller, 1997; Sniderman et al. 1997). A brief outline of the relationships between CM and VLDL, and cholesterol-rich lipoproteins (LDL-cholesterol and HDL-cholesterol), is given here to illustrate how an elevated postprandial lipaemic response may be related to other lipid abnormalities of the 'metabolic syndrome', such as low HDL, raised fasting triacylglycerols and a preponderance of the LDL-3 (small dense) subtype.

The processes thought to be involved in the relationship between TRL and cholesterolrich lipoproteins, and which may explain the link between elevated triacylglycerols and accelerated atherogenesis, have been reviewed elsewhere (Sethi et al. 1993; Patsch, 1994) and an outline summary of these events is shown in Fig. 2.

An exaggerated response to a fat-containing meal may be due to overproduction of $\mathrm{CM}$ or VLDL, or may reflect slower clearance of these particles by the rate-regulatory step in triacylglycerol hydrolysis and removal, which is mediated by lipoprotein lipase (EC 3.1.1.34; LPL). Accumulation of partially-hydrolysed remnant particles may also contribute to the elevated triacylglycerol response, since due to their poor recognition by hepatic receptors, there is reduced uptake of these cholesterol-enriched particles by receptor-mediated pathways. The net consequence of these defects is increased retention of TRL within the circulation, providing greater opportunity for neutral-lipid exchange, 


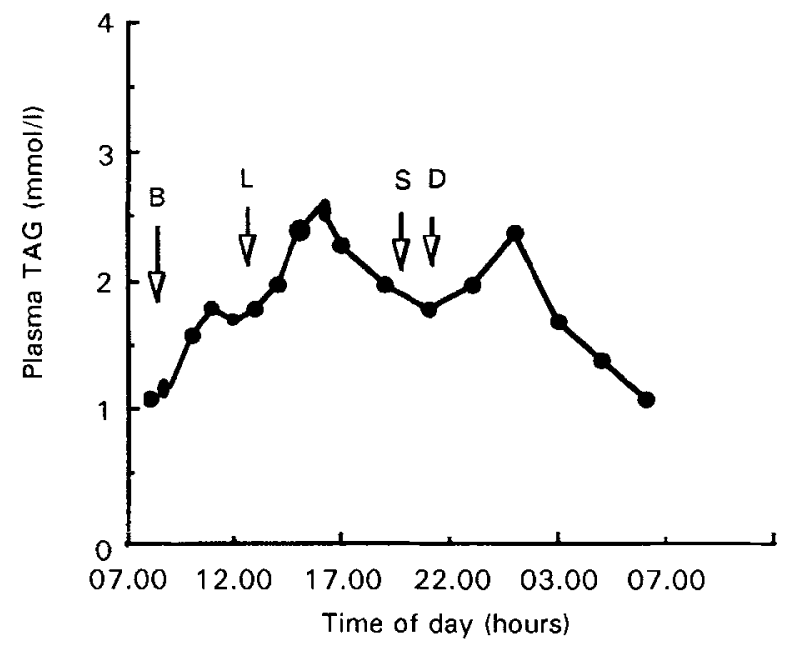

Fig. 1. Plasma triacylglycerol (TAG) responses $(24 \mathrm{~h})$ in a 27 -year-old man given a breakfast (B), lunch (L), snack (S) and dinner (D) at the times indicated.

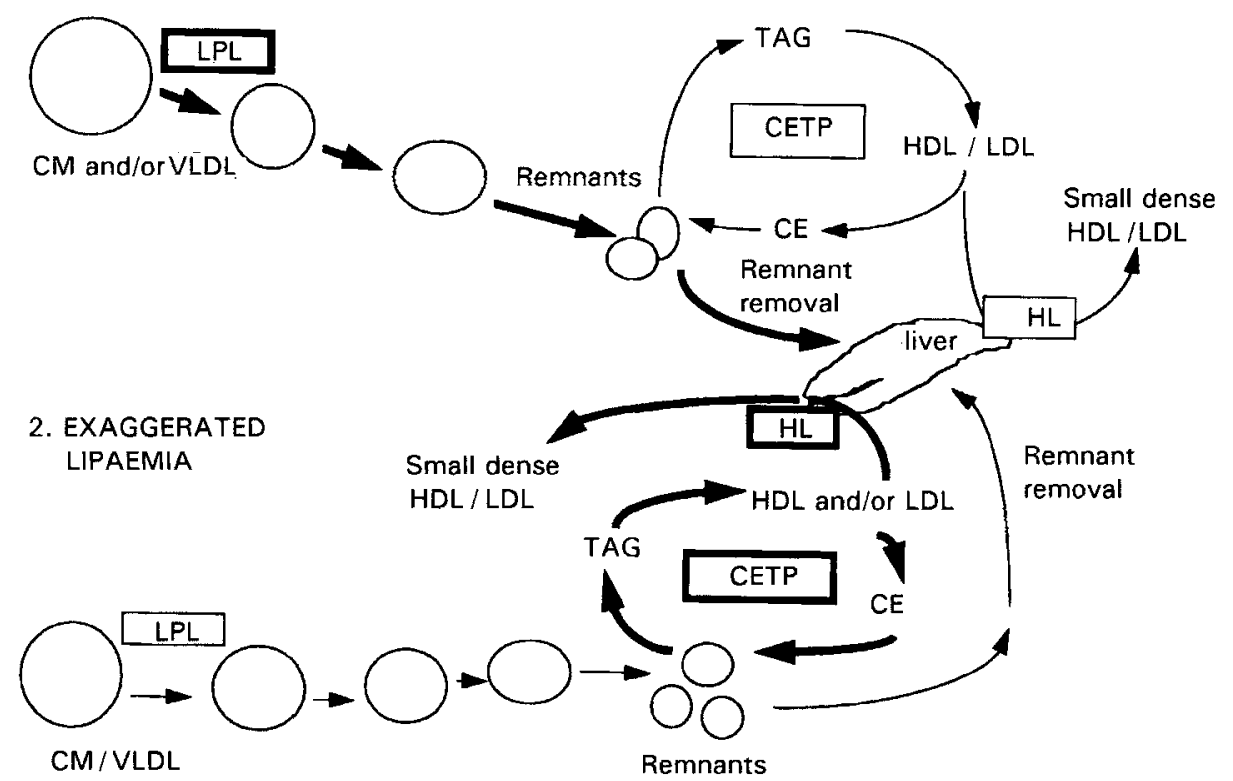

Fig. 2. Diagrammatic representation of the atherogenic consequences of impaired triacylglycerol (TAG) tolerance. 1. Nomal lipaemia: (-), TAG-rich lipoprotein (TRL) production rates and clearance and remnant removal rates; (-), exchange with HDL and LDL and hepatic lipase (EC 3.1.1.3; HL) action. 2. Exaggerated lipaemia: (-), clearance of TRL and removal of remnants; (-), exchange with HDL and LDL and HL action. CM, chylomicron; CE, cholesteryl ester; CETP, CE transfer protein; LPL, lipoprotein lipase (EC 3.1.1.34). 
catalysed by cholesteryl ester transfer protein (CETP), which mediates the reciprocal transfer of triacylglycerol and cholesterol between TRL and HDL and LDL. The net consequence of these transfers is triacylglycerol accumulation on HDL and LDL, and cholesterol on CM and VLDL and their remnants. The triacylglycerol-enriched HDL and LDL act as good substrates for the hepatic lipase (EC 3.1.1.3; HL) enzyme, resulting in formation of small dense $\mathrm{HDL}\left(\mathrm{HDL}_{3}\right)$ and $\mathrm{LDL}$ (LDL-3). The former are catabolized rapidly, resulting in reduced circulating HDL levels. The small dense LDL and the cholesterol-enriched remnant particles are reputed to have greater atherogenic potential due to their prolonged retention within the circulation (Hazzard \& Bierman, 1976; Nigon et al. 1991), their ability to induce foam cell formation (Parthasarathy et al. 1989; Kinoshita et al. 1990; Georgopoulos et al. 1994) and, in the case of LDL, its greater susceptibility to undergo oxidation (Chait $e$ t al. 1993). CM remnants have also been shown to penetrate the endothelium in much the same way as LDL and HDL (Mamo \& Wheeler, 1994). As discussed elsewhere (Griffin, 1997), the importance of CETP and HL in determining quantitative and qualitative changes in HDL and LDL are the subject of debate and ongoing work, and for the purpose of the present account most emphasis will be placed on the role of dietary fatty acids in modulating postprandial triacylglycerol response, since present evidence suggests it is elevated triacylglycerol concentrations which drive the events described previously.

\section{EFFECTS OF DIETARY FATTY ACIDS ON POSTPRANDIAL LIPAEMIA}

In order to evaluate the effect of meal fatty acid composition on the extent of postprandial lipaemia, a number of investigators have compared triacylglycerol responses to single meals of varying fatty acid composition. Some have used circulating markers of intestinally-derived lipoproteins such as retinyl esters and apolipoprotein (apo) B-48 to discriminate intestinal (CM) and hepatic (VLDL) contributions to the postprandial lipaemic response to meals. Variations in postprandial lipaemia in response to meals of different fatty acid composition could reflect differences in the rate of synthesis, secretion or clearance of the intestinally-derived $\mathrm{CM}$ and the rate of production and clearance of their remnants. It is also possible that hepatic uptake of fatty acids released from CM, and the nature of the fatty acids in CM remnants presented to the liver could influence, acutely, the synthesis and secretion of VLDL, and thereby the hepatic contribution to the triacylglycerol response to meal consumption. Although some studies have attempted to address the relative contributions of CM and VLDL, the limitation of retinyl esters as specific markers of CM (Krasinski et al. 1990), and the paucity of studies using apo B-48 (Foger \& Patsch, 1993), make it difficult to draw conclusions regarding the involvement of CM and VLDL in fatty acid-induced variations in postprandial lipaemia. Similar limitations apply to studies which have attempted to address the question of adaptational responses to diets of different fatty acid composition. In these studies, subjects fed on diets for periods ranging from 2 to 8 weeks are usually given test meals of standard fatty acid composition to evaluate effects of background diet on postprandial lipaemia. In these models, any effect of diet could reflect adaptational responses in enterocytic and hepatic enzymes involved in CM and VLDL synthesis, as well as in the lipoprotein and hepatic lipases which regulate clearance of triacylglycerol and remnant particles respectively. Other possible loci for adaptational effects of dietary fatty acids include receptors, such as the remnant and LDL receptors which regulate the uptake and removal of CM and VLDL remnant particles. 


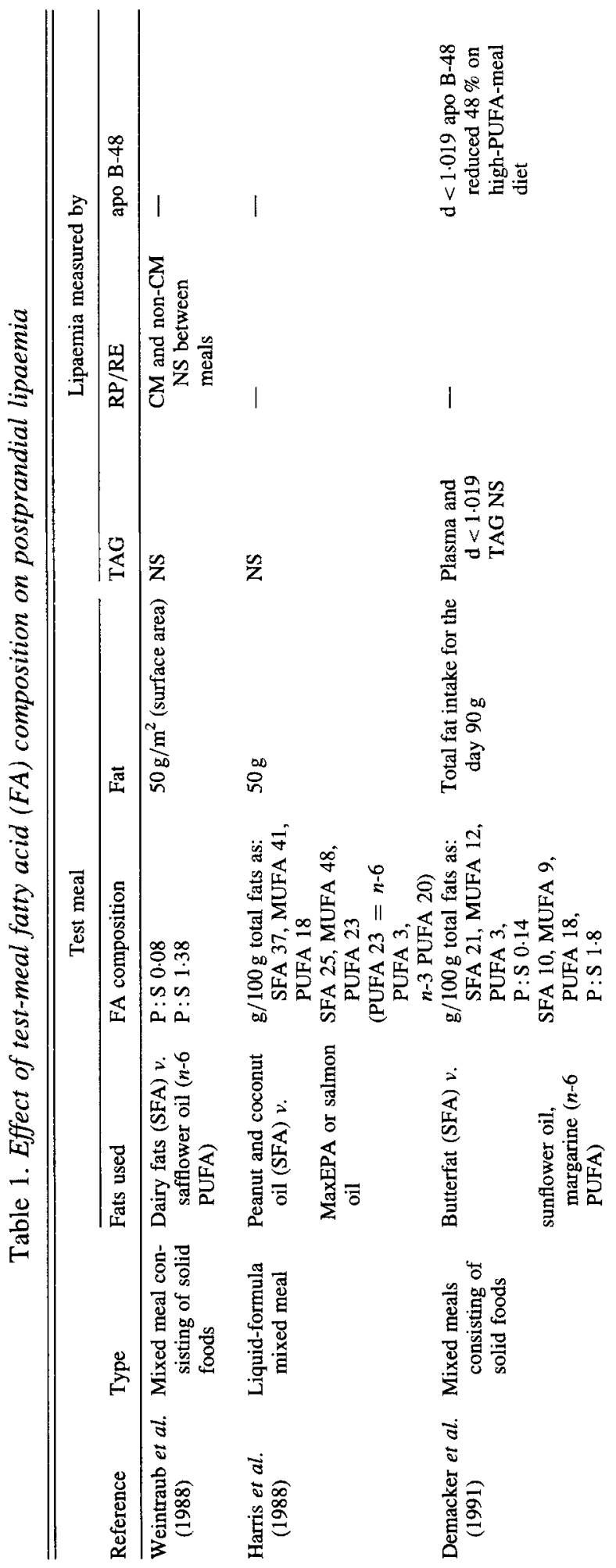



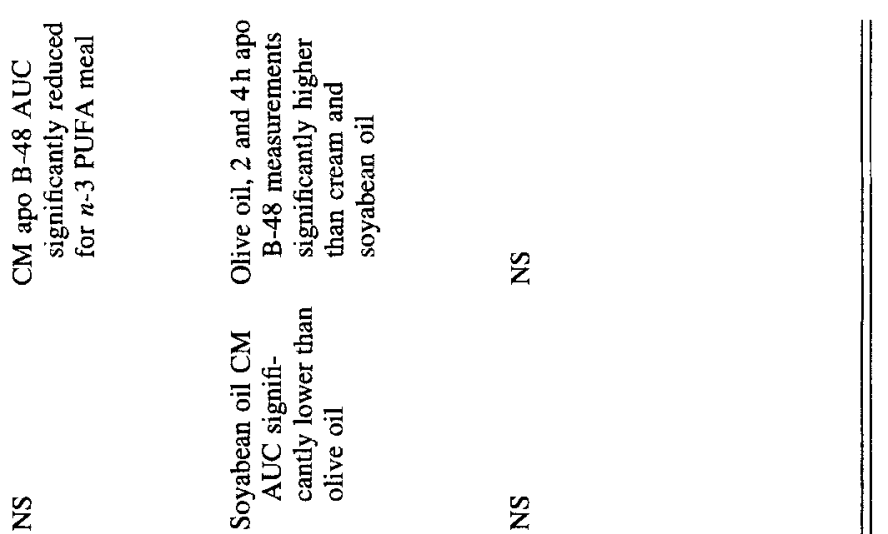

|

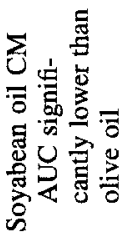

忩

$z$

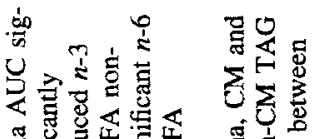

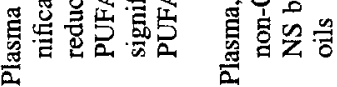

象

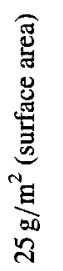

$\stackrel{s}{q}$

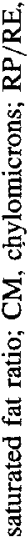

$\stackrel{\infty}{q}$

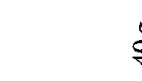

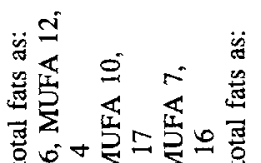

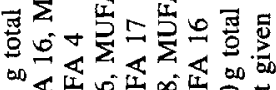

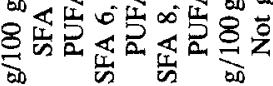
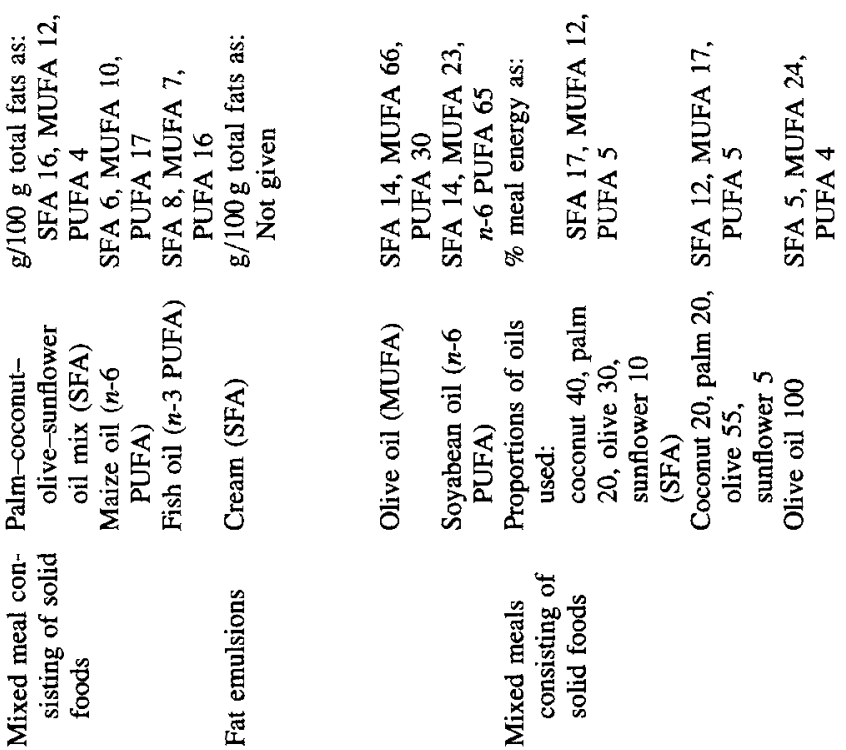

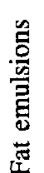
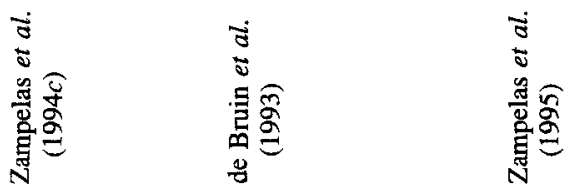

胥 영 $n 8$

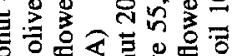

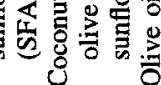


Although a number of animal feeding studies have used tracer techniques and measurements of tissue enzymes and receptor activities to investigate mechanisms involved in effects of specific fatty acids on CM metabolism (Groot et al. 1988; Levy et al. 1991), the present review mainly addresses human studies, most of which are limited to measurement of circulating postprandial lipid responses to meals.

\section{ACUTE EFFECTS OF DIETARY FATTY ACIDS ON POSTPRANDIAL LIPAEMIA}

There are five studies reported in the literature which have measured postprandial lipaemic responses to meals of different fatty acid composition (Harris et al. 1988; Weintraub et al. 1988; de Bruin et al. 1993; Zampelas et al. 1994c, 1995) and one which has studied combined effects of both meal and background diet (Demacker et al. 1991; Table 1). Comparison of the findings from these studies is difficult, because even when similar comparisons are being made, e.g. SFA (saturated fatty acids) $v . n-6$ polyunsaturated fatty acids (PUFA), the nature of the fats and oils used has not always been the same. Similarly the amount of fat used in the test meal and the duration of postprandial follow-up after the meal are frequently different. In one instance, liquid-formula meals have been given (Harris et al. 1988) rather than solid foods and in one case, lipid emulsions (de Bruin et al. 1993), without addition of carbohydrate or protein, have been used. In most instances, lipaemic response has been evaluated by measurement of plasma and sometimes CM triacylglycerol response.

Weintraub et al. (1988) compared postprandial lipoprotein responses to meals comprising predominantly SFA or $n-6$ PUFA. The SFA meal consisted of scrambled egg, cheese, bread and a milk shake, whereas the $n-6$ PUFA meal contained turkey, bread and a milk shake made with safflower oil. No differences in postprandial retinyl palmitate or triacylglycerol responses to the two meals were observed. This is in slight contrast to findings from our study (Zampelas et al. 1994c) in which subjects were given three test meals which were identical apart from the oils used, which were mixed (SFA), maize ( $n-6$ PUFA) and fish oil (long-chain $n$-3 PUFA). The mixed oil was formulated to represent the current UK dietary fatty acid intake. The meals consisted of rice with vegetables, salad and a milk shake and the test oils were added as salad dressing and in a milk shake. Postprandial triacylglycerol response to the $n-6$ PUFA (maize oil) meal was lower than that to the mixed-oil meal but the major difference found was in response to the meal containing long-chain $n$-3 PUFA (fish oil), where marked attenuation in postprandial triacylglycerol levels was seen. Measurement of apo B-48 in the triacylglycerol-rich fraction confirmed that the attenuation represented reduced circulation of $\mathrm{CM}$ particles (Peel et al. 1993). In an earlier study, Harris et al. (1988) found no difference in postprandial triacylglycerol response to liquid test meals containing either a mixture of peanut oil and cocoa butter (saturated-fat meal) or MaxEPA (fish-oil meal). A recent study (Yahia et al. 1996) has shown that addition of only small amounts of long-chain $n$-3 PUFA to a standard fat-containing test meal can significantly reduce the postprandial lipaemic response compared with the same meal without added long-chain $n-3$ PUFA, and suggests that the fatty acids in fish oil alter the rate of synthesis and/or removal of $\mathrm{CM}$ triacylglycerol, independently of the remaining fatty acid substrate supplied.

There is also some disparity in the findings of studies which have compared effects of monounsaturated fatty acids (MUFA) and other major fatty acid classes on postprandial lipaemia. de Bruin et al. (1993) reported that the lipaemic response (postprandial triacylglycerol or retinyl palmitate measurement) was slightly higher when lipid emulsions containing olive oil were fed, than when cream or sunflower oil emulsions were fed. We 
compared postprandial triacylglycerol, apo B-48 and retinyl ester responses in sixty volunteers given test meals in which SFA were progressively replaced by monounsaturated fatty acids (MUFA), and found no significant difference in plasma or CM fraction triacylglycerol, apo B-48 or retinyl ester responses (Zampelas et al. 1994a; Jackson et al. 1995). The three test meals fed contained 12, 17 and $24 \%$ dietary energy as MUFA, representing respectively current UK, current Mediterranean and previous Mediterranean MUFA intakes. This study suggests that varying meal MUFA composition across a range which reflects worldwide dietary variation has no effect on postprandial lipaemic response.

Based on this small number of studies it is concluded that similar postprandial lipaemic responses are observed when meals consisting of predominantly SFA, MUFA or $n-6$ PUFA are fed, but when meals containing significant amounts of $n-3$ PUFA are given, postprandial lipaemia is attenuated.

\section{EFFECTS OF BACKGROUND DIETARY FATTY ACID INTAKE ON POSTPRANDIAL LIPAEMIA}

There are a number of different types of studies which have evaluated the impact of altered background diet on postprandial lipaemia. Four studies used a whole-diet approach in which total dietary fat was altered (Harris \& Connor, 1980; Harris et al. 1988; Weintraub et al. 1988; Demacker et al. 1991; Table 2), whereas four studies used capsule supplements (Brown \& Roberts, 1991; Harris \& Windsor, 1991; Williams et al. 1992; Harris \& Muzio, 1993; Table 2) and one study incorporated microencapsulated oils into conventional foods (Lovegrove et al. 1997; Table 2), to partially alter background dietary fatty acid intake. One other study has compared effects of different PUFA- and MUFA-containing diets on fasting and postprandial triacylglycerol values but the limited data presented make the findings difficult to compare with other studies and are not included in the table (Lichtenstein et al. 1993).

In those studies which have altered total background diet, most investigators have carried out randomized controlled studies with measurement of subjects responses to a standard meal at the end of a control and a test-diet period. In some instances, investigators have chosen to measure response to a test meal which has the same fatty acid composition as the background diet being fed. This is the case with the study of Demacker et al. (1991) who altered the diets of free-living subjects so that either butterfat or safflower oil was the predominant fat used in cooking and in meals prepared at their work place. After 3 weeks on each diet, subjects responses to a breakfast, lunch and dinner were monitored over a $24 \mathrm{~h}$ period. On each occasion the fat content and composition of the test meals given were the same as those of the background diet. In this type of study it is difficult to distinguish the effect of altering the background diet from that of altering the test-meal fatty acid composition. However, this particular study suggests that when a diet and a test meal consisting largely of $n-6$ PUFA are fed, postprandial triacylglycerol and apo B-48 responses are lower than those when a diet and a meal rich in SFA are fed.

The careful study of Weintraub et al. (1988) was carried out in a metabolic unit with subjects randomized to receive three different background diets for 3 weeks over a 12week period. The responses of the subjects to two different test meals were evaluated at the end of each dietary period. Lipaemic responses of the subjects were reduced when the background diet consisted of $n-6$ or $n-3$ PUFA, although it was only the reduction with $n-3$ PUFA which was statistically significant when a saturated-fat meal was used as the test meal. The attenuating effects of the $n-6$ PUFA diet were greater when an $n-6$ PUFA test meal was given than when a SFA test meal was given, supporting the findings of Demacker et al. (1991), which indicates there may be synergism between the adaptational response 


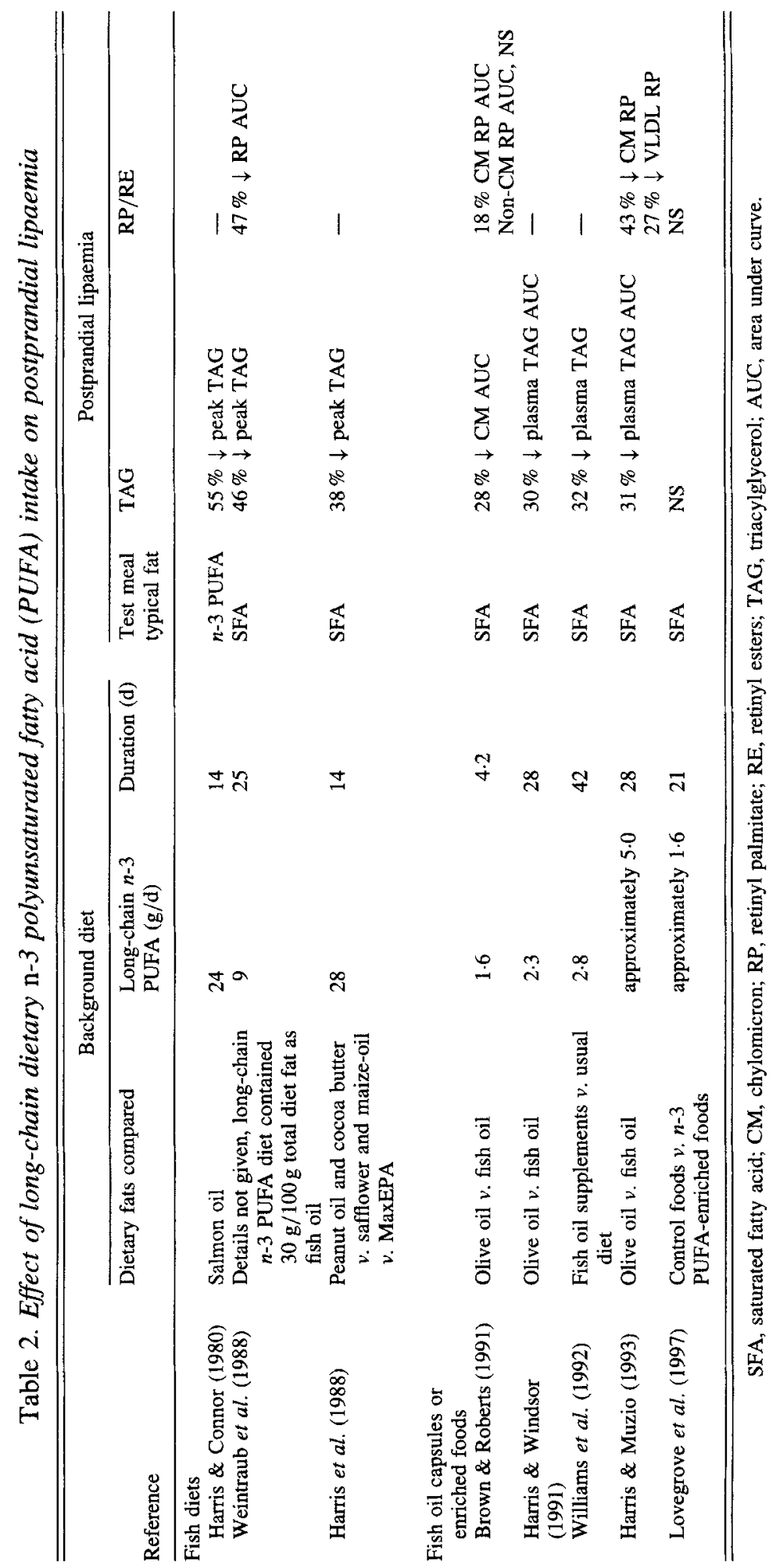


and acute-meal mechanism. Harris et al. (1988) also found hypolipaemic effects of a diet rich in fish oil in a study in which they fed either a control diet consisting of peanut oil and cocoa butter or a diet consisting of salmon oil or MaxEPA as background.

Data obtained from these diet studies suggest that the dietary fats fed in the background diet may markedly influence subjects' responses to a standard fat-containing meal and that, in particular, diets enriched with fish oils containing long-chain n-3 PUFA significantly increase triacylglycerol tolerance.

In the light of the convincing evidence for potent triacylglycerol-lowering effects of dietary long-chain $n$-3 PUFA, one question which needs to be addressed is the level at which these fatty acids need to be fed in the normal human diet in order to maintain optimally low levels of postprandial triacylglycerols. Useful information is available from studies which have used capsule preparations (Table 2). From these studies it would appear that diets containing 1.6-2.8 g long-chain $n-3$ PUFA result in $30 \%$ reduction in postprandial lipaemia. Higher levels than this, e.g. $5 \mathrm{~g} / \mathrm{d}$, can achieve an even greater degree of reduction. This level of supplementation is considerably higher than habitual levels of intake of long-chain $n-3$ PUFA found in most human diets, since in the UK average levels of intake are approximately $0.2 \mathrm{~g} / \mathrm{d}$ (Gregory et al. 1991). This compares with intake levels of $12 \mathrm{~g} / \mathrm{d}$ for linoleic acid, the major $n-6$ PUFA, and $1.3 \mathrm{~g} / \mathrm{d}$ for $\alpha$ linolenic acid, the precursor of $n-3$ PUFA. If, as might be expected, future dietary strategies for prevention of CHD consider the need for reductions in fasting and postprandial triacylglycerol levels, an important question which must be addressed is the form (either precursor or long-chain), and level, at which the $n$-3 PUFA should be provided in the diet.

\section{EFFECTS OF HABITUAL FATTY ACID INTAKE ON POSTPRANDIAL LIPAEMIA}

Although the dietary studies described previously are designed to address the question of adaptational responses to altered diet, it is likely that these responses develop over many weeks or even months, depending on the site and mechanism involved. It is possible that many of the studies conducted to date have been too short to reveal the full extent of changes in lipoprotein metabolism which occur when fatty acid intake is markedly altered in human diets. This is particularly so in the light of the large number of sites through which fatty acids may mediate effects on triacylglycerol metabolism. This means that differences may not become evident in short-term dietary studies where the different diets have only been fed for a limited period of time (usually weeks). This conclusion is supported by a recent study we have carried out which measured postprandial responses to standard meals in subjects living in southern and northern Europe whose diets closely reflected the typical diets of their country (Williams et al. 1995; Zampelas et al. 1997). We found the pattern of lipaemic response to identical meals was very different in southern than northern Europeans and that, in particular, subjects from southern Europe showed a marked early rise in triacylglycerol with rapid return to fasting values, whereas northern Europeans showed a slow sluggish rise in triacylglycerols which did not return to fasting values until 8 or $9 \mathrm{~h}$ after the meal (Fig. 3). The most noticeable difference between the two groups was the lower triacylglycerol concentrations in the late postprandial period in the southern European group. Whether these findings have any significance to differences in risk of CHD between these two populations is not known, but they are consistent with the observation that elevations in late postprandial triacylglycerol values, between 6 and $10 \mathrm{~h}$ after a meal, have been identified as a significant risk factor for CHD in a number of casecontrol studies (Groot et al. 1991; Patsch et al. 1992), and in a study of the offspring of subjects with CHD (Uiterwaal et al. 1994). 


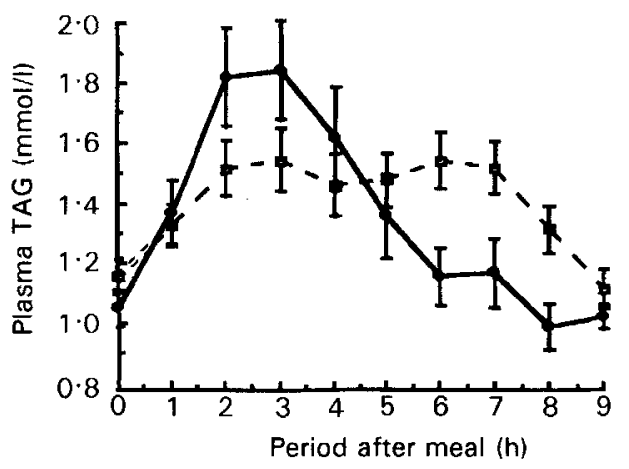

Fig. 3. Postprandial plasma triacylglycerol (TAG) responses to standard mixed test meals containing $40 \mathrm{~g}$ fat in young male subjects from: (-), southern ( $(30)$; ( $\square-\square$ ), northern Europe ( $n$ 30). (From Williams et al. 1995.)

\section{MECHANISM INVOLVED IN FATTY ACID-MEDIATED ALTERATIONS IN POSTPRANDIAL LIPAEMIA}

A detailed discussion of the mechanisms involved in fatty acid-mediated alterations in postprandial lipaemia is beyond the scope of the present review, although some consideration of possible sites has been given previously. Human test-meal studies suggest variations in meal fatty acid composition have modest effects on postprandial lipaemia, apart from marked attenuation of triacylglycerol responses when long-chain $n-3$ PUFA are fed. Longer-term diet studies suggest that $n-6$ PUFA may have moderate triacylglycerol-lowering effects, but marked hypolipaemic effects of long-chain $n$-3 PUFA are evident from a number of diet and supplementation studies. Animal studies have shown effects of meal fatty acid composition on postprandial lipaemia to depend in part on differences in CM size, with the PUFA producing CM of larger size which appear to act as better substrates for the LPL enzyme (Groot et al. 1988; Levy et al. 1991). There is also some evidence from animal studies (Table 3) to suggest that PUFA and MUFA increase the activity of LPL and thereby enhance triacylglycerol clearance. Animal studies are generally in agreement that diets containing large amounts of PUFA and MUFA significantly increase either post-heparin LPL (Groot et al. 1988; van Heek \& Zilversmit, 1990) or adipose tissue LPL activity (Levy et al. 1991; Murphy et al. 1993) and one study has shown increased gene expression of LPL in epididymal fat pads of animals fed on fish oils (Murphy et al. 1993). However, human studies have generally failed to find increased post-heparin LPL activity when high-PUFA diets are fed (Harris et al. 1988; Weintraub et al. 1988; Nozaki et al. 1991), although one study has shown elevated post-heparin LPL activity $9 \mathrm{~h}$ following meals enriched with long-chain $n$-3 PUFA (Zampelas et al. 1994b; Table 3). Conflicting findings in these type of studies may be due to lack of precision and specificity of the post-heparin LPL measurements. Post-heparin LPL measurements include both LPL from skeletal muscle and adipose tissue, but animal studies suggest the activating effects of long-chain $n$ - 3 PUFA are localized to adipose tissue, so that these nonspecific measurements may fail to detect single-site responses. However, further evidence that the effects of long-chain $n$-3 PUFA do not reflect activation of LPL was provided by Harris \& Muzio (1993), who found that enrichment of diets with fish oil fatty acids, although markedly reducing postprandial responses to standard meals, did not accelerate removal of an artificial lipid emulsion when this was given intravenously. These findings 
Table 3. Effects of dietary fatty acids on indices of lipoprotein lipase (EC 3.1.1.34; LPL) activity

\begin{tabular}{|c|c|c|c|}
\hline Reference & Species & Diets & LPL measurement \\
\hline \multicolumn{4}{|l|}{ Animal studies } \\
\hline Groot et al. (1988) & Rat & $\begin{array}{l}\text { Meals containing either palm or } \\
\text { sunflower oil }\end{array}$ & $\begin{array}{l}\text { Post-heparin LPL } 10 \text { and } 12 \mathrm{~h} \\
\text { after meal significantly higher } \\
\text { in sunflower oil-fed rats }\end{array}$ \\
\hline $\begin{array}{l}\text { van Heek \& } \\
\text { Zilversmit (1990) }\end{array}$ & Rabbit & $\begin{array}{l}\text { Diets containing either } 140 \mathrm{~g} \\
\text { coconut oil or } 140 \mathrm{~g} \text { olive } \\
\text { oil } / \mathrm{kg}\end{array}$ & $\begin{array}{l}\text { Post-heparin LPL three times } \\
\text { higher in olive oil-fed animals } \\
\text { after } 49 \mathrm{~d}\end{array}$ \\
\hline Levy et al. (1991) & Rat & $\begin{array}{l}\text { Diets containing MCT, coconut or } \\
\text { safflower oils }\end{array}$ & $\begin{array}{l}\text { Adipose tissue LPL activity sig- } \\
\text { nificantly higher in safflower } \\
\text { oil-fed animals }\end{array}$ \\
\hline Murphy et al. (1993) & Rat & $\begin{array}{l}\text { Diets containing mixed, maize or } \\
\text { fish oils }\end{array}$ & $\begin{array}{l}\text { Adipose tissue LPL activity high- } \\
\text { er (NS) and LPL mRNA sig- } \\
\text { nificantly higher in fish oil-fed } \\
\text { animals }\end{array}$ \\
\hline \multicolumn{4}{|l|}{ Human studies } \\
\hline Weintraub et al. (1988) & & $\begin{array}{l}\text { Background diets typified by SFA, } \\
n-6 \text { PUFA or } n-3 \text { PUFA }\end{array}$ & $\begin{array}{l}\text { Post-heparin LPL activity higher } \\
\text { (NS) on } n-3 \text { PUFA diet }\end{array}$ \\
\hline Harris et al. (1988) & & $\begin{array}{l}\text { Background diets typified by SFA, } \\
n-6 \text { PUFA or } n-3 \text { PUFA }\end{array}$ & $\begin{array}{l}\text { Post-heparin LPL and HL activ- } \\
\text { ities not significantly different } \\
\text { for the three diets }\end{array}$ \\
\hline Nozaki et al. (1991) & & $\begin{array}{l}\text { Diet supplemented with } 10 \mathrm{~g} \text { long- } \\
\text { chain } n-3 \text { PUFA/d } \\
\text { Hypertriacylglycerolaemic sub- } \\
\text { jects }\end{array}$ & $\begin{array}{l}\text { Post-heparin LPL and HL activ- } \\
\text { ities not significantly different } \\
\text { with } n-3 \text { PUFA supplementa- } \\
\text { tion }\end{array}$ \\
\hline
\end{tabular}

MCT, medium-chain triacylglycerols; SFA, saturated fatty acids; PUFA polyunsaturated fatty acids; HL, hepatic lipase (EC 3.1.1.3).

have directed attention towards the enterocyte as a possible site of action of the acute effects of long-chain $n$-3 PUFA and studies using CaCo-2 cells have confirmed the inhibitory effects of these fatty acids on lipogenic enzymes involved in CM synthesis (Chautan et al. 1990; Murthy et al. 1990). The different patterns of triacylglycerol response observed in the comparison of northern and southern Europeans (Williams et al. 1995; Zampelas et al. 1997) also indicate potential effects of fatty acids on the gastrointestinal processing of dietary fat and the need for further studies of effects of fatty acids on the molecular processes involved in CM synthesis, assembly and secretion.

\section{CONCLUSION}

An exaggerated postprandial lipaemic response is becoming increasingly recognized as an important lipid risk factor for CHD. Relatively few studies of effects of meal and background dietary fatty acid composition on postprandial lipoprotein responses have been conducted, in contrast to the situation for fasting lipoproteins measurements, where many hundreds of studies have been reported in the literature.

Meal and background dietary fatty acid intake can influence both the extent and the pattern of postprandial triacylglycerol responses to fat ingestion, with the greatest effect observed for the long-chain $n-3$ PUFA which have potent triacylglycerol-lowering properties, both when added to individual meals, and when included in the habitual diet. 
Further studies are required to determine the optimum type and balance of dietary fatty acids which can maintain a low postprandial response to meal consumption. Mechanisms underlying modulatory effects of dietary fatty acids need further investigation.

\section{REFERENCES}

Brown, A. J. \& Roberts, D. C. K. (1991). Moderate fish oil intake improves lipemic response to a standard fat meal. Arteriosclerosis \& Thrombosis 11, 457-466.

Chait, A., Brazer, R. L., Tribble, D. L. \& Krauss, R. M. (1993). Susceptibility of small, dense, low density lipoproteins to oxidative modification in subjects with the atherogenic lipoprotein phenotype, pattern $B$. American Journal of Medicine 94, 350-356.

Chautan, M., Charbonnier, M., Leonardi, J., Andre, M., Lafont, H. \& Nalbone, G. (1990). Modulation of lipid chylomicron-synthesizing enzymes in rats by the dietary $(n-6):(n-3)$ fatty acid ratio. American Institute of Nutrition 121, 1305-1310.

Cohn, J. S. (1994). Postprandial lipid metabolism. Current Opinion in Lipidology 5, 185-190.

de Bruin, T. W. A., Brouwer, C. B., van Linde-Sibenius Trip, M., Jansen, H. \& Erkelens, D. W. (1993). Different postprandial metabolism of olive oil and soybean oil: a possible mechanism of the high-density lipoprotein conserving effect of olive oil. American Journal of Clinical Nutrition 589, 477-483.

Demacker, P. N. M., Reijnen, I. G. M., Katan, M. B., Stuyt, P. M. J. \& Stalenhoef, A. F. H. (1991). Increased removal of remnants of triglyceride-rich lipoproteins on a diet rich in polyunsaturated fatty acids. European Journal of Clinical Investigation 21, 197-203.

Department of Health (1991). Dietary Reference Values for Food Energy and Nutrients for the United Kingdom. Report on Health and Social Subjects no. 41. London: H.M. Stationery Office.

Department of Health. (1994). Nutritional Aspects of Cardiovascular Disease. Report on Health and Social Subjects no. 46. London: H.M. Stationery Office.

Foger, B. \& Patsch, J. R. (1993). Strategies and methods for the assessment of disturbed postprandial lipid metabolism. Current Opinion in Lipidology 4, 428-433.

Georgopoulos, A., Kafonek, S. D. \& Raikhel, I. (1994). Diabetic postprandial triglyceride-rich lipoproteins increase esterified cholesterol accumulation in THP-1 macrophages. Metabolism 43, 1063-1072.

Groot, P. H. E., de Boer, B. C. J., Haddeman, E., Houtsmuller, U. M. T. \& Hulsmann, W. C. (1988). Effect of dietary fat composition on the metabolism of triacylglycerol-rich plasma lipoproteins in the postprandial phase in meal-fed rats. Journal of Lipid Research 29, 541-555.

Groot, P. H. E., van Stiphout, W. A. H. J., Krauss, X. H., Jansen, H., van Tol, A., van Ramshorst, E., Chin-On, S., Hofman, A., Cresswell, S. R. \& Havekes, L. (1991). Postprandial lipoprotein metabolism in normolipidemic men with and without coronary artery disease. Arteriosclerosis \& Thrombosis 11, 653-662.

Gregory, J., Foster, K., Tyler, H. \& Wiseman, M. (1991). The Dietary and Nutritional Survey of British Adults. London: H.M. Stationery Office.

Griffin, B. A. (1997). Low-density lipoprotein subclasses: mechanisms of formation and modulation. Proceedings of the Nutrition Society 56, 693-702.

Harris, W. S. \& Connor, W. E. (1980). The effects of salmon oil upon plasma lipids, lipoproteins and triglyceride clearance. Transactions of the American Physicians Association 43, 179-184.

Harris, W. S., Connor, W. E., Alam, N. \& Illingworth, D. R. (1988). Reduction of postprandial triglyceridemia in humans by dietary $n-3$ fatty acids. Journal of Lipid Research 299, 1451-1460.

Harris, W. S. \& Muzio, F. (1993). Fish oil reduces postprandial triglyceride concentrations without accelerating lipid-emulsion removal rates. American Journal of Clinical Nutrition 58, 68-74.

Harris, W. S. \& Windsor, S. L. (1991). n-3 Fatty acid supplements reduce chylomicron levels in healthy volunteers. Joumal of Applied Nutrition 43, 5-15.

Havel, R. J. (1994). Postprandial hyperlipidemia and remnant lipoproteins. Current Opinion in Lipidology 5, $102-109$.

Hazzard, W. R. \& Bierman, E. L. (1976). Delayed clearance of chylomicron remnants following vitamin Acontaining fat loads on broad-beta disease (type II hyperlipoproteinemia). Metabolism 25, 777-801.

Hodis, H. N. \& Mack, W. J. (1995). Triglyceride-rich lipoproteins and the progression of coronary artery disease. Current Opinion in Lipidology 6, 209-214.

Jackson, K. G., Knapper, J. M. E., Zampelas, A., Gould, B. J., Lovegrove, J. A., Wright, J. \& Williams, C. M. (1995). Apolipoprotein B-48 and retinyl ester responses to meals of varying monounsaturated fatty acid contents. Atherosclerosis $115, \mathrm{~S} 16$.

Karpe, F. (1997). Postprandial lipid metabolism in relation to coronary heart disease. Proceedings of the Nutrition Society 56, 671-678.

Karpe, F. \& Hamsten, A. (1995). Postprandial lipoprotein metabolism and atherosclerosis. Current Opinion in Lipidology 6, 123-129. 
Karpe, F., Steiner, G., Uffelman, K., Olivecrona, T. \& Hamsten, A. (1994). Postprandial lipoproteins and progression of coronary atherosclerosis. Atherosclerosis 106, 83-97.

Kinoshita, M., Krul, E. S. \& Schonfield, G. (1990). Modification of the core lipids of low density lipoproteins produces selective alterations in the expression of apo B-100 epitopes. Journal of Lipid Research 31, 710-718.

Krasinski, S. D., Cohen, J. S., Russell, R. M. \& Schaefer, E. J. (1990). Postprandial vitamin A metabolism in humans: A reassessment of the use of plasma retinyl esters as markers for intestinally derived chylomicrons and their remnants. Metabolism 39, 357-365.

Levy, E., Roy, C. C., Goldstein, R., Bar-On, H. \& Ziv, E. (1991). Metabolic fate of chylomicrons obtained from rats maintained on diets varying in fatty acid composition. Journal of the American College of Nutrition 10 , 69-78.

Lichtenstein, A. H., Ausman, L. M., Carrasco, W., Jenner, J. L., Gualtieri, L. J., Goldin, B. R., Ordovas, J. M. \& Schaefer, E. J. (1993). Effects of canola, corn, and olive oils on fasting and postprandial plasma lipoproteins in humans as part of a National Cholesterol Education Program Step 2 Diet. Arteriosclerosis \& Thrombosis 13, $1533-1542$.

Lovegrove, J. A., Brooks, C. N., Murphy, M. C., Gould, B. J. \& Williams, C. M. (1997). Use of manufactured foods enriched with fish oils as a means of increasing long-chain n-3 PUFA intake. British Journal of Nutrition 78 (In the Press).

Mamo, J. C. L. \& Wheeler, J. R. (1994). Chylomicrons and their remnants penetrate rabbit thoracic aorta as efficiently as do smaller macromolecules, including low density lipoprotein, high density lipoprotein and albumin. Coronary Heart Disease 5, 695-705.

Miller, G. J. (1997). Postprandial lipid metabolism and thrombosis. Proceedings of the Nutrition Society 56, $739-744$.

Murphy, M. C., Zampelas, A., Puddicombe, S. M., Furlonger, N. P., Morgan, L. M. \& Williams, C. M. (1993). Pretranslational regulation of the expression of the lipoprotein lipase gene by dietary fatty acids. British Journal of Nutrition 70, 727-736.

Murthy, S., Albright, E., Mathur, S. N. \& Field, F. J. (1990). Effect of eicosapentaenoic acid on triacylglycerol transport in CaCo-2 cells. Biochimica et Biophysica Acta 1045, 147-155.

Nigon, F., Lesnik, P., Rouis, M. \& Chapman, M. J. (1991). Discrete subspecies of human low density lipoproteins are heterogeneous in their interaction with the cellular LDL receptor. Journal of Lipid Research 32, 1741-1753.

Nozaki, S., Garg, A., Vega, G. L. \& Grundy, S. M. (1991). Postheparin lipolytic activity and plasma lipoprotein response to $n-3$ polyunsaturated fatty acids in patients with primary hypertriglyceridemia. American Journal Clinical Nutrition 53, 638-642.

Parthasarathy, S., Quinn, M. T., Schwenke, D. C., Carew, T. E. \& Steinberg, D. (1989). Oxidative modification of beta-very low density lipoprotein. Potential role in monocyte recruitment and foam cell formation. Arteriosclerosis 9, 398-404.

Patsch, J. R. (1994). Triglyceride-rich lipoproteins and atherosclerosis. Atherosclerosis 110, S22-S26.

Patsch, J. R., Miesenbock, G., Hopferwieser, T., Muhlberger, V., Knapp, E. \& Dunn, J. K. (1992). Relation of triglyceride metabolism and coronary artery disease. Arteriosclerosis \& Thrombosis 12, 1336-1345.

Peel, A. S., Zampelas, A., Gould, B. J., Ah-Sing, E., Chakraborty, J. C., Howland, R. J. \& Williams, C. M. (1993). Measurement of apolipoprotein B-48 with a novel specific antibody reveals two peaks of intestinal origin. Proceedings of the Nutrition Society 52, 289A.

Sethi, S., Gibney, M. \& Williams, C. M. (1993). Postprandial lipoprotein metabolism. Nutrition Research Reviews 6, 161-183.

Sniderman, A. D., Cianflone, K., Summers, L., Fielding, B. \& Frayn, K. (1997). The acylation-stimulating protein pathway and regulation of postprandial metabolism. Proceedings of the Nutrition Society, 56, 703-712.

Uiterwaal, C. S. P. M., Grobbee, D. E., Witteman, J. C. M., van Stiphout, W.-A. H. J., Krauss, X. H., Havekes, L. M., de Bruin, A. M., van Tol, A. \& Hofman, A. (1994). Postprandial triglyceride response in young adult men and familial risk for coronary atherosclerosis. Annals of Internal Medicine 121, 576-583.

van Heek, M. \& Zilversmit, D. B. (1990). Postprandial lipemia and lipoprotein lipase in the rabbit are modified by olive and coconut oil. Arteriosclerosis 10, 421-429.

Weintraub, M. S., Zechner, R., Brown, A., Eisenberg, S. \& Breslow, J. (1988). Dietary polyunsaturated fats of the $\omega-6$ and $\omega-3$ series reduce postprandial lipoprotein levels. Journal of Clinical Investigation 82, 1884-1893.

Williams, C. M., Moore, F., Morgan, L. \& Wright, J. (1992). Effects of $n-3$ fatty acids on postprandial triglyceride and hormone concentrations in normal subjects. British Journal of Nutrition 68, 655-666.

Williams, C. M., Zampelas, A., Jackson, K. G., Gould, B. J., Wright, J., Kafatos, A. \& Kapsokephalou, M. (1995). Postprandial triacylglycerol responses to meals of varying monounsaturated fatty acid content in UK and Greek subjects. Atherosclerosis 115, S46.

Yahia, N., Songhurst, C. \& Sanders, T. A. B. (1996). Effect of different patterns of fat intake on postprandial lipaemia and factor VII coagulant activity. Proceedings of the Nutrition Society 55, 227A.

Zampelas, A., Culverwell, C. C., Knapper, J. M. E., Jackson, K., Gould, B. J., Wright. J. \& Williams, C. M. (1994a). Olive oil and postprandial lipaemia: A study on the effect of meals of different olive oil content on postprandial lipid levels in healthy men. Proceedings of the Nutrition Society 54, 164A. 
Zampelas, A., Knapper, J. M. E., Jackson, K. G., Culverwell, C. C., Wilson, J., Gould, B. J. \& Williams, C. M. (1995). Postprandial triacylglycerol and apolipoprotein B-48 responses to meals of varying monounsaturated fatty acid content in young UK subjects. Atherosclerosis 115, S46.

Zampelas, A., Morgan, L. M., Murphy, M. \& Williams, C. M. (1994b). Effects of dietary fatty acid composition on postprandial insulin, GIP and lipoprotein lipase activity. European Journal of Clinical Nutrition 48, 2634.

Zampelas, A., Peel, A., Gould, B. J., Wright, J. \& Williams, C. M. (1994c). Polyunsaturated fatty acids of the $n$ 6 and $n-3$ series: effects on postprandial lipid and apolipoprotein levels in healthy men. European Journal of Clinical Nutrition 48, 88-96.

Zampelas, A., Roche, H., Kapsokefalou, M., Knapper, J. M. E., Jackson, K. G., Pentaris, E., Tornatis, M., Hatzis, C., Gibney, M. J., Kafatos, A., Gould, B. J., Wright, J. \& Williams, C. M. (1997). Differences in postprandial lipaemic responses but not traditional plasma lipid coronary risk indicators between Northern and Southern Europeans. Atherosclerosis, Thrombosis and Vascular Biology (In the Press). 